\title{
СТРАТЕГИЧЕСКАЯ НЕСТАБИЛЬНОСТЬ НА БАЛКАНАХ КАК СЛЕДСТВИЕ ВНЕШНЕЙ ПОЛИТИКИ США
}

\begin{abstract}
Аннотация
Присутствие США на Балканах в начале 1990-х годов имело определенный положительный эффект. Однако продолжение американского пребывания на данной территории после (краткосрочного) разрешения этих кризисов повлекло за собой катастрофические последствия. Балканские страны во всех отношениях периферийны, тенденция депопуляции вызывает беспокойство, а разница в экономических показателях по отношению к западным странам более выражена, чем в 1990-е годы. Очевидная нестабильность носит стратегический характер, уровень доверия очень низок как среди балканских государств и народов, так и по отношению к коллективному Западу. Было продемонстрировано, что присоединение к наднациональным структурам и принесение в жертву собственного суверенитета и целостности не являются сами по себе решением проблемы. Следовательно, нельзя искать решения ряда вопросов в существующих рамках, созданных Соединенными Штатами.
\end{abstract}

Ключевые слова: Балканы, США, НАТО, ЕС, внешняя политика, стратегическая нестабильность.

DOI: $10.51180 / R P S .2021 .18 .1 .010$

\section{Автор}

\section{Душан Пророкович}

Доктор политических наук, руководитель Центра евразийских исследований, научный сотрудник, ассоциированный профессор Института международной политики и экономики (Белград, Сербия)

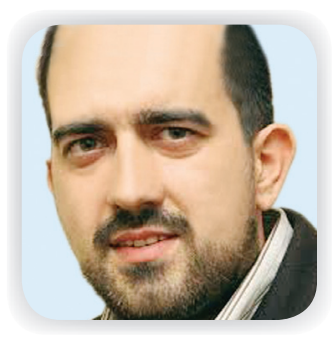

Введение: Определение понятия стратегической нестабильности и цель исследования

П о словам Александра Панарина, стратегическая нестабильность возникает в результате деконструкции суверенных государств и национальных сообществ, что является целью глобалистского проекта под руководством США с помощью (про)западных союзников. Это включает в себя подчинение государств и даже отдельных лиц наднациональным органам управления, глобальной элите, которую никто не контролирует. С одной стороны, этот проект служит освоению ресурсов планеты, а с другой, широко пропагандирует ценность всеобщего просвещения [11]. В этой статье по- нятие стратегической нестабильности рассматривается в более широком контексте. Цель исследования - подтвердить тезис о том, что внешнеполитическое позиционирование США в наблюдаемых пространственных рамках способствовало возникновению стратегической нестабильности. Главный исследовательский вопрос заключается в том, вызвали ли США своей внешней политикой стратегическую нестабильность в региональной балканской системе?

Пространственные рамки исследования охватывают территории суверенных государств - Греции, Болгарии, Албании, Северной Македонии, Черногории, Боснии и Герцеговины, Сербии (включая территорию Косово), 
Румынии и Хорватии ${ }^{1}$. Хронологические рамки ограничены периодом с 1990 года и до начала эры однополярности, которая в долгосрочной перспективе сформировала новую конфигурацию региональных отношений. Исследование проводилось на основе реалистских теорий международных отношений с использованием методов сравнения, контент-анализа и синтеза. Для целей исследования использовалась современная историографическая, политическая, аналитическая и экономическая литература, первоисточники, связанные с государственными стратегиями и межгосударственными соглашениями, а также заявления официальных лиц, имеющие отношение к теме данной статьи.

\section{Балканы после холодной войны: Идем на Запад!}

Чтобы передать атмосферу в балканских государствах в начале рассматриваемого периода, мы можем использовать стихи из популярной тогда песни британской музыкальной группы Pet Shop Boys 1993 года: «Вместе — мы взлетим так высоко. / Вместе - попрощаемся со всеми нашими друзьями / Вместе - начнем жизнь заново / Вместе - это то, что мы сделаем!» Песня носит символическое название - Go West (Иди на Запад)! Припев: «Жизнь там мирная / Иди на Запад - под открытым небом / Иди на Запад - там, где небо голубое / Идем на Запад - вот что мы будем делать». Достаточно было избавиться от мрачного коммунистического наследия и отправиться на Запад, там все — голубое небо, свежий воздух,

1 Безусловно, идут оживленные дискуссии о том, какие страны можно отнести к балканским. Это уже давно вопрос не географии, а политики. Если применить традиционное мнение о границах Балканского полуострова (реки Купа, Сава и Дунай, а также Черное море, Мраморное море, Эгейское море, Ионическое море и Адриатическое море), Турция и Словения могут подпадать под определение балканских стран. мирная жизнь! В коммунистической Югославии эта тенденция наблюдается с середины 1980-х годов, в Румынии после свержения Чаушеску, а в Болгарии и Албании после падения коммунистических властей. За прозападной ориентацией обществ последовали политические элиты. Правда, в разных государствах процесс перестройки шел различными путями.

Этот период характеризуется социальными потрясениями, развитием коррупции, политическими протестами и вооруженными конфликтами. Весной 1990 года в Румынской Трансильвании возникла огромная межэтническая напряженность между румынами и венграми [9]. Массовые протесты в Болгарии в конце 1996 и начале 1997 года, также известные как "Болгарская зима», привели к отставке премьерминистра Жана Василева Виденова [7]. В 1997 году в Албании разразилась кратковременная гражданская война, вызванная обвалом финансовых пирамид, блокадой государственных учреждений и крахом части аппарата безопасности. В столкновениях, которые было трудно прекратить, погибло около 1600 человек [1]. Конфликт начался в январе и закончился в июле после того, как была проведена операция «Альба» - привлечены многонациональные миротворческие силы во главе с Италией, призванные помочь албанскому правительству восстановить закон и порядок ${ }^{2}$ [16]. Дестабилизационные процессы перешли из Албании в сербский край Косово и Метохия и внесли свой вклад в неблагоприятное развитие событий на территории, которая преимущественно населена этническими албанцами. Наиболее драматические события случились в Югославии: переход к «новой эре» произошел через кровавую гражданскую

2 Совет Безопасности ООН принял резолюцию 1101 об учреждении операции "Альба". В ней участвовали одиннадцать стран: Австрия, Бельгия, Дания, Франция, Греция, Италия, Португалия, Румыния, Словения, Испания и Турция. 
войну, закончившуюся военной агрессией НАТО против Югославии. Присоединение к коллективному Западу, выраженное через заинтересованность в членстве в ЕС и НАТО, формируется сначала через конфликт, а затем через сотрудничество. В то первое десятилетие посткоммунистических времен не было голубого неба, открытого воздуха, мирной жизни! Но кризисы, которые не могли быть разрешены без США или их союзников, неизбежно заставили общественное мнение поверить в то, что дорога на Запад безальтернативна и что присоединение к коллективному Западу неизбежно.

К чему привело это неизменное движение балканских государств на Запад? Количество статей в научных журналах о плюсах этого движения измеряется десятками тысяч. Практически создана отдельная «научная дисциплина» европейской интеграции, основанная на концепции либерального интернационализма [4]. Несомненно, экономические показатели балканских государств изменились с 1990 года по сегодняшний день (см. табл. 1). Если посмотреть на данные, представленные МВФ и государственными учреждениями США, номинальный ВВП увеличился в четыре раза в Албании, в 3,5 раза в Румынии, в 3,5 раза в Греции и почти в два раза в совокупности для государств бывшей Югославии (включая Словению и Косово), в то время как в Болгарии ВВП на душу населения по паритету покупательной способности возрос в 2,5 раза.

На первый взгляд, можно сделать вывод, что сейчас жизнь на Балканах лучше, чем до 1990-х годов. Но в то же время Балканы - это зона интенсивной эмиграции. Население сокращается быстрыми темпами, и это связано не только с уменьшением количества новорожденных, но и, прежде всего, с усилением тенденции переселения в западные страны.

В некоторой степени абсурдны примеры Болгарии, Румынии и Хорватии. Эти три государства являются полноправными членами ЕС и НАТО, но население «бежит» оттуда, как и из соседних стран. Разве они вступили в ЕС и НАТО для поощрения эмиграции? Почему уезжает население, если Балканы сегодня живут лучше, если экономические показатели выше, чем в предыдущие десятилетия?

Ответ на эти вопросы нельзя найти в абсолютных показателях роста ВВП, инвестиций и средней заработной платы. Ответ на эти вопросы могут дать относительные данные, когда мы сравниваем показатели балканских

Таблица 1

Экономические показатели балканских государств (1990-2019) [5]

\begin{tabular}{|l|c|c|c|c|}
\hline \multicolumn{1}{|c|}{ Страна } & $\begin{array}{c}\text { ППС на душу } \\
\text { населения (1990) }\end{array}$ & $\begin{array}{c}\text { ППС на душу } \\
\text { населения (2019) }\end{array}$ & ВВП (1990) & ВВП (2019) \\
\hline Албания & 2976 & 14467 & 3800 & 15276 \\
\hline Босния и Герцеговина & & 15626 & 20203 \\
\hline Болгария & 9922 & 24331 & 51200 & 68563 \\
\hline Хорватия & & 29945 & & 60759 \\
\hline Греция & 13425 & 30914 & 56300 & 205349 \\
\hline Северная Македония & & 17294 & & 12550 \\
\hline Сербия & & 19025 & 79800 & 249695 \\
\hline Румыния & 7611 & 31226 & 129500 & 51475 \\
\hline Югославия & 5464 & & & \\
\hline
\end{tabular}


Таблица 2

Количество жителей в балканских странах (2001-2021) [3; 8; 14]

\begin{tabular}{|l|c|c|c|}
\hline \multicolumn{1}{|c|}{ Страна } & 2001 & 2021 & $2021 / 2001$ \\
\hline Албания & 3069225 & 2877797 & -191428 \\
\hline Босния и Герцеговина & 3798953 & 3280819 & -518134 \\
\hline Болгария & 7932984 & 6948445 & -984539 \\
\hline Греция & 10964020 & 10423054 & -540966 \\
\hline Македония & $2022547(2002)$ & 1832696 & -189851 \\
\hline Румыния & $21680974(2002)$ & 19237691 & -2443283 \\
\hline Сербия & $7498001(2002)$ & 6908000 & -590001 \\
\hline Хорватия & 4492049 & 4105267 & -386782 \\
\hline Черногория & $620145(2003)$ & 621718 & 1573 \\
\hline Косово (ООН) & $1850000(\sim)$ & $1350000(\sim)$ & -500000 \\
\hline ВСЕГО & 63928898 & 57585487 & -6343411 \\
\hline
\end{tabular}

государств с примерами других стран. За рассматриваемый период номинальный ВВП Великобритании вырос примерно в 3,5 раза, США - примерно в четыре раза и Австрии - примерно в 4,5 раза.

С одной стороны, западные экономики росли быстрее, чем балканские, поэтому разница в абсолютном или относительном выражении стала даже больше, чем во время холодной войны или биполярного периода. С другой стороны, новые игроки (в первую очередь отдельные азиатские страны) превзошли балканские государства, не только оставив их позади, но и уменьшив их значение в мировой экономике. Балканские страны хотели стать частью коллективного Запада, политические элиты стремились к ЕС и НАТО, но даже несмотря на эти устремления, Балканы стали просто периферией западного мира. Экономически и политически периферийные и опустошенные по численности населения балканские государства сейчас находятся в худшем положении, чем в начале процесса в 1990-х годах. Это повод для недовольства. И любое недовольство рано или поздно становится причиной не- стабильности. «Открытые границы» и относительно легкие процедуры эмиграции в богатые европейские страны представляют собой своего рода «клапан недовольства». Остается открытым вопрос, как долго может продлиться такой подход и какие результаты он принесет в долгосрочной перспективе.

\section{США и Балканы после холодной войны: «На Восток!»}

В отличие от балканских обществ, которые отправились на Запад, движимые туманной целью «голубого неба, открытого воздуха, мирной жизни", Выходит, что США ясно знали, чего они хотят, когда направлялись на Восток! В геополитическом контексте такой подход позволил установить контроль над балканской частью Римленда. "Увеличение количества стран - участниц НАТО и, как следствие, расширение американского влияния, безусловно, имело свои геостратегические причины. Балканский полуостров представляет собой зону контакта между водами Адриатического и Черного морей в более узком географическом смысле (вдоль оси Запад-Восток), то есть конти- 
Таблица 3

Расширение НАТО на Балканы (1952-2004-2020)

\begin{tabular}{|c|c|c|}
\hline Страна & $\begin{array}{l}\text { Членство } \\
\text { в НАТО }\end{array}$ & Геостратегическое значение для НАТО \\
\hline Греция & c 1952 & $\begin{array}{l}\text { Обеспечение позиции в Восточном Средиземноморье; наблюдение за } \\
\text { коммунистическими государствами в непосредственной близости (Бол- } \\
\text { гария, Югославия, Албания); контроль г. Отранто; гармонизация внешней } \\
\text { политики и политики безопасности с Турцией с целью предотвращения } \\
\text { возникновения крупномасштабного межгосударственного конфликта; } \\
\text { дальнейшее обеспечение контроля над Дарданеллами и Босфором. }\end{array}$ \\
\hline Болгария & c 2004 & $\begin{array}{l}\text { Выход на побережье Черного моря; контроль стратегического направ- } \\
\text { ления от Адриатики до Черного моря; обеспечение доступа к Ближнему } \\
\text { Востоку; приближение к юго-западной границе России. }\end{array}$ \\
\hline Румыния & c 2004 & $\begin{array}{l}\text { Выход на побережье Черного моря; контроль стратегического направле- } \\
\text { ния от Центральной Европы до дельты Дуная; пограничный контроль с } \\
\text { Украиной; приближение к юго-западной границе России. }\end{array}$ \\
\hline Словения & c 2004 & $\begin{array}{l}\text { Обеспечение позиции в северной Адриатике; контроль стратегического } \\
\text { направления по долине Савы до впадения в Дунай. }\end{array}$ \\
\hline Албания & с 2009 & $\begin{array}{l}\text { Обеспечение позиции на юге Адриатики (контроль над г. Отранто); кон- } \\
\text { троль стратегического направления от Адриатического моря до Черного } \\
\text { моря (через территорию Косово и/или Северной Македонии в порты } \\
\text { Болгарии). }\end{array}$ \\
\hline Хорватия & с 2009 & $\begin{array}{l}\text { Обеспечение позиции в центральной части Адриатических вод; контроль } \\
\text { над стратегическими маршрутами от равнины Паннония (Венгрия) до } \\
\text { Адриатического моря (большинство из них проходят через территорию } \\
\text { Боснии и Герцеговины); контроль стратегического направления по долине } \\
\text { Савы до впадения в Дунай. }\end{array}$ \\
\hline Черногория & c 2017 & $\begin{array}{l}\text { Создание Адриатической тройки путем соединения с Албанией и Хорвати- } \\
\text { ей, в результате чего НАТО полностью обеспечивает коммуникационный } \\
\text { маршрут от Триестского залива до Пелопоннеса; контроль над южной } \\
\text { веткой транспортной магистрали Белград - Бар. }\end{array}$ \\
\hline $\begin{array}{l}\text { Северная } \\
\text { Македония }\end{array}$ & c 2020 & $\begin{array}{l}\text { Завершение контроля над южным маршрутом стратегического направле- } \\
\text { ния от Адриатики до Черного моря; контроль над «балканской вертика- } \\
\text { лью» - ключевым региональным транспортным маршрутом (Афины - } \\
\text { Салоники - Скопье - Ниш - Белград - Будапешт), который проходит } \\
\text { через Моравско-Вардарскую долину. }\end{array}$ \\
\hline
\end{tabular}

нентальную зону Центральной Европы и Ближнего Востока в более широком смысле (вдоль оси Северо-Запад и ЮгоВосток). Доминирование на Балканах имело смысл в контексте ограничения присутствия или долгосрочного проникновения российского влияния в приграничную зону (что представляет собой первый шаг в процессе обеспечения собственных границ) - в направлении Кавказ - Черное море (новосозданные независимые государства Грузия, Азербайджан, Армения, Украина, а также союзники СССР в то время - Румыния и Болгария) и для непрерывного планирования деятельности на Ближнем Востоке» [12. - С. 120]. Процесс расширения НАТО на Балканах показан в табл. 4 [13. - С. 557-579].

\section{Американская внешняя политика на Балканах и стратегическая нестабильность: Клинтоны против Киссинджера}

В конце лета 1995 года, когда силы НАТО бомбили позиции армии Сербской Республики в Боснии и Герцего- 
вине, Генри Киссинджер заявил: «я не понимаю, что мы пытаемся сделать при помощи бомбардировок» [6]. Киссинджер пророчески предупредил Вашингтон о том, что может произойти на Балканах: "Это не закончится, даже если мы победим в этом сражении. Мы не можем оставаться там на постоянной основе» [Там же]. Администрация во главе с Клинтоном не проявила особого интереса к данным предупреждениям.

Чтобы оправдать процесс 1999 года и представить его как гуманитарную интервенцию, американцам пришлось лоббировать «независимость Косово». Вот почему в 2008 году США позволили албанцам провозгласить независимость, пообещав, что коллективный Запад их поддержит. Таким образом, Косово остается одним из крупнейших замороженных конфликтов в мире и ключевой проблемой региональной безопасности на Балканах.

Чтобы еще больше усугубить положение "непослушной Сербии", США вложили средства в разрыв государственного союза с Черногорией и сыграли активную роль в организации референдума 2006 года. На референдуме, полном нарушений, за «установление независимости» проголосовало «небольшое большинство» (квалифицированное большинство за решение составило $55 \%$, а за роспуск союзного государства - 55,49\%). В результате черногорское общество оставалось постоянно поляризованным. Чтобы предотвратить негативные последствия, которые могут возникнуть в результате этой поляризации в будущем, после смещения Мило Джукановича Черногория «втягивается» в НАТО [15].

В то же время, чтобы усилить позиции албанцев на Балканах, Вашингтон активно лоббирует вступление Албании в НАТО. Однако это ставит в совершенно новый контекст ярко выраженные сепаратистские устремления македонских албанцев. В целях предотвращения "боснийского» или «косовского» сценария в Македонии, американская внешняя политика начинает ориентироваться на «втягивание» этой страны в НАТО. Таким образом, НАТО становится единственным гарантом сохранения территориальной целостности. Однако «втянуть» в НАТО было нелегко, потому что Греция блокировала это, требуя, чтобы бывшая югославская республика сменила название. Наконец, решение было найдено в изменении названия государства на Республику Северная Македония. Но, как и в случае с Черногорией, граждане этот шаг не поддерживают. Изменение названия на Северную Македонию стало решением проблемы для дальнейшего расширения НАТО. Вместо этого автоматически возникли две новые проблемы [17]. Во-первых, македонское общество осталось поляризованным, а межэтническая напряженность между славянскими македонцами и албанцами усилилась (албанцы на референдуме полностью поддержали изменение названия, потому что это подрывает македонскую идентичность). Во-вторых, поскольку эта «политика шантажа» принесла Греции результаты в отношении (Северной) Македонии, Болгария начала применять тот же метод. София блокирует продолжение переговоров между Северной Македонией и ЕС до тех пор, пока не будут решены вопросы идентичности (включая вопрос названия языка, который, по утверждениям Софии, является только диалектом болгарского!). Агрессивная политика Болгарии в отношении Северной Македонии, проводимая министром обороны Красимиром Каракачановым, вызвала реакцию Греции и Сербии, которые рассматривают ее как возрождение старых планов «горизонтального раздела» страны между Софией и Тираной. Таким образом, Греция снова втягивается в этот кризис.

Повторяясь, поскольку для Косово не существует решения, на которое согласилась бы Сербия, во время президентского срока Дональда Трампа 
рассматривался новый подход, выраженный в термине "делимитация". Никто точно не объяснил, что это будет означать, но было понятно, что это приведет к разделению Косово на южную албанскую часть (около 85\% территории) и северную часть сербского меньшинства. Кроме того, чтобы предотвратить неблагоприятный исход в Боснии и Герцеговине (далее - БиГ), западные державы организовали новую кампанию по необходимости дедеитонизации этой страны. Становится очевидным, что если "делимитация» в Косово узаконена, то необходимо узаконить и раздел БиГ. Американская политика в БиГ основана на пересмотре мирного соглашения, упразднении образований и создании унитарного государства. Институты Сербской Республики резко реагируют, принимая ряд решений по «защите компетенций», и ведущий сербский политик Милорад Додик (в настоящее время член трехстороннего президентства БиГ, бывший премьер-министр и президент Республики (ербской) открыто выступает за положение по статусному референдуму и отделению. Таким образом, БиГ вступает в новый этап, который всего за два года (2018-2020 гг.) стал не просто кризисом, связанным с ситуацией в Косово, а кризисом сам по себе. Понятно, что события в БиГ вызывают реакцию в Хорватии, которая не поддержит унитаризацию страны, потому что это ухудшит и без того плохое положение боснийских хорватов и скорее приведет к появлению трех образований вместо двух (хорваты, наконец, получат свою территориальную автономную единицу в БиГ).

Также за ситуацией в Румынии пристально следят в связи с другим замороженным конфликтом, в котором очень заинтересован Бухарест, - Приднестровье. Таким образом, американское желание видеть Молдову в НАТО получило совершенно новое измерение. Дополнительной причиной осложнения отношений на Балканах являются но- вые элементы американской внешней политики. С 2014 года распространяются мнения о российском пагубном влиянии, а с 2019 года также и о китайском, о котором говорят все чаще и чаще [10. - С. 2-11]! Хотя китайские инвестиции хорошо воспринимаются, часто они единственные в балканских странах, а энергетическая безопасность региона напрямую зависит от сотрудничества с Россией, США и ЕС пытаются навязать полностью другой взгляд на балканские элиты и общества. Это создает условия для возникновения новых кризисов и новых поляризаций.

\section{Заключение. Причины стратегической нестабильности и их решение}

Американская внешняя политика руководствовалась подходом Клинтона, а не Киссинджера. Односторонние действия, постоянное навязывание решений, не пользующихся общественной поддержкой, шантаж и давление (которое проявляется с 2014 года в требованиях дистанцировать балканские государства от России и Китая) создали «воспламеняющуюся атмосферу», нарушили межгосударственные и межэтнические отношения и способствовали ускорению поляризации во всех обществах. Слова Киссинджера подтверждаются: «Это не может закончиться, даже если мы выиграем в этом. Мы не можем оставаться там в постоянной оккупации».

Присутствие США на Балканах в начале 1990-х годов имело определенный положительный эффект. Однако продолжение американского присутствия на данной территории после (краткосрочного) разрешения этих кризисов повлекло за собой катастрофические последствия. Американская внешняя политика следовала максималистским геополитическим устремлениям. Балканы должны были стать «эксклюзивной американской зоной». Следование вектору внешней 
политики США стало непременным условием для любого политика или политической партии, которые хотят узаконить свое положение и участвовать в управлении. Те, кто отказывается от этого, становятся маргиналами. Однако задача обеспечения региональной безопасности оказалась намного сложнее, чем предполагалось. Несмотря на расширение НАТО и частичное расширение ЕС, выгоды невелики. Балканские страны во всех отношениях периферийны, тенденция депопуляции вызывает беспокойство, а разница в экономических показателях по отношению к западным странам более выражена, чем в 1990-е годы. Воспринимаемая нестабильность носит стратегический характер, уровень доверия очень низок как среди балканских государств и народов, так и по отношению к коллективному
Западу. Было показано, что присоединение к наднациональным структурам и принесение в жертву собственного суверенитета и целостности не являются решением проблемы сами по себе. Следовательно, нельзя искать решения ряда вопросов в существующих рамках, которые создали Соединенные Штаты. Для решения открытых вопросов необходимо искать компромиссы с учетом интересов всех балканских факторов региональной безопасности, а также принимая во внимание не западные внешние факторы региональной безопасности, интересы которых на Балканах столь же легитимны, как и интересы Соединенных Штатов. В противном случае, стратегическая нестабильность может привести к очень неблагоприятным исходам и худшим результатам, чем мы видим сегодня.

\section{Литература}

1. Abrahams F. Modern Albania: From Dictatorship to Democracy in Europe. N.Y.: NYU Press, 2015. - P. 219.

2. CIA World Factbook1990 // Central Inteligency Agency. - URL: https://www.cia.gov/theworld-factbook/about/cover-gallery/1990-cover/ (retrived 07.10.2021).

3. Countries in the world by population (2021) // Worldometer - Data based on the latest United Nations Population Division estimates. — URL: https://www.worldometers.info/worldpopulation/population-by-country/ (retrived 07.10.2021).

4. Dimitrijević D., Lađevac l. (eds.). Proširenje Evropske unije na zapadni Balkan: zbornik radova sa medjunarodne konferencije [EU Enlargement in the Western Balkans: Proceedings of an International Conference]. - Beograd: Institut za međunarodnu politiku I privredu, 2009. $313 \mathrm{p}$.

5. IMF World Economic Outlook Database // Report for Selected Countries and Subjects: October 2021. —URL: https://www.imf.org.en/Publications/WEO/weo-database/2021/October/ weo-report?c (retrived 04.10.2021).

6. Kissinger $\mathrm{H}$. Henry Kissinger says that Bosnia never existed as a country and is an artificial creation // YouTube. - URL: https://www.youtube.com/watch?v=KCNxXET2gZs (retrived 29.09.2021).

7. Kormusheva K. Change of Behavior in Transition: The Bulgarian Protests in January 1997 // Polish Sociological Review. - 2003. - No. 144. - P. 435-443.

8. Kuzmanovski B. Severna Makedonija za 19 godina izgubila 190.000 ljudi [Northern Macedonia has lost 190,000 people in 19 years] // Radio Slobodna Evropa. — 01.10.2021. — URL: https:// www.slobodnaevropa.org/a/severna-makedonija-popis-stanovni\%C5\%A1tva/31487780.html (retrived 02.10.2021).

9. Lipcsey I., Gherman S., Severin A. Romania and Transylvania in the 20th Century. - Buffalo: Corvinus Pub., 2006. - P. 193.

10. Mitić $A$. Belt and Road Strategic Communication Resilience: Lessons from the SERBIA BRI Frame Analysis // Working paper. - 2017. — No. 19. Budapest: China - CEE Institute, 2017. - P. 1-17.

11. Панарин А.С. Стратегическая нестабильность XXI века. - М.: Алгоритм, Эксмо, 2003. $558 \mathrm{c.}$ 
12. Ponomareva E., Proroković D. NATO vs Russia: Impact on Balkan regional security // Europe in Changes: The old continent at a new crossroads / Eds. Zakić K., Demirtaş B. - Belgrade: Institute of International Politics and Economics, 2021. - P. 117-138.

13. Proroković D. Geopolitika Srbije: položaj i perspektive na početku XXI veka [Geopolitics of Serbia: position and perspectives at the beginning of the 21st century]. - Beograd: Službeni glasnik, 2018. - $1028 \mathrm{p}$.

14. Proroković D. Koliko je zaista Albanaca na Kosovu [How many Albanians are there in Kosovo?] // Radio Sputnik. — 09.03.2019. — URL: https://rs.sputniknews.com/20190309/albancikosovo--1119093800.html (retrived 21.10.2021).

15. Raković A. Otcepljenje Crne Gore (2006): novostečena, a ne obnovljena državnost [The Secession of Montenegro (2006): New Statehood, Not Renewed Statehood] // Srpska politička misao. - 2018. - No. 2. - P. 195-210.

16. United Nations Security Council Resolution 1101. - New York: UN, 1997. - P. 1-2.

17. Veliu $L$. The sounds of silence: Democracy and the referendum on (FYRO)/(North) Macedonia // New Perspectives. - 2021. — No. 29 (2). - P. 165-186. 